\title{
Physiological levels of ATP negatively regulate proteasome function
}

Hongbiao Huang ${ }^{1, *}$, Xiaoyan Zhang ${ }^{1, *}$, Shujue $\mathrm{Li}^{1,{ }^{*}}$, Ningning Liu ${ }^{1, *}$, Wen Lian ${ }^{1, *}$, Emily McDowell ${ }^{2}$, Ping Zhou ${ }^{1}$, Canguo Zhao ${ }^{1}$, Haiping Guo ${ }^{1}$, Change Zhang ${ }^{1}$, Changshan Yang ${ }^{1}$, Guangmei Wen ${ }^{1}$, Xiaoxian Dong ${ }^{1}$, Li Lu ${ }^{1}$, Ningfang $\mathrm{Ma}^{1}$, Weihua Dong ${ }^{1}$, Q Ping Dou ${ }^{1,3,4}$, Xuejun Wang ${ }^{1,2}$, Jinbao Liu ${ }^{1}$

${ }^{1}$ Protein Modification and Degradation Lab, Department of Pathophysiology, Guangzhou Medical College, Guangzhou, Guangdong 510182, China; ${ }^{2}$ Division of Basic Biomedical Sciences, Sanford School of Medicine of the University of South Dakota, Vermillion, SD 57069, USA; ${ }^{3}$ The Prevention Program, Barbara Ann Karmanos Cancer Institute, Wayne State University, Detroit, MI 48201, USA; ${ }^{4}$ Department of Pathology, School of Medicine, Wayne State University, Detroit, MI 48201, USA

Intracellular protein degradation by the ubiquitin-proteasome system is ATP dependent, and the optimal ATP concentration to activate proteasome function in vitro is $\sim 100 \mu \mathrm{M}$. Intracellular ATP levels are generally in the low millimolar range, but ATP at a level within this range was shown to inhibit proteasome peptidase activities in vitro. Here, we report new evidence that supports a hypothesis that intracellular ATP at the physiological levels bidirectionally regulates $26 \mathrm{~S}$ proteasome proteolytic function in the cell. First, we confirmed that ATP exerted bidirectional regulation on the $26 \mathrm{~S}$ proteasome in vitro, with the optimal ATP concentration (between 50 and $100 \mu \mathrm{M}$ ) stimulating proteasome chymotrypsin-like activities. Second, we found that manipulating intracellular ATP levels also led to bidirectional changes in the levels of proteasome-specific protein substrates in cultured cells. Finally, measures to increase intracellular ATP enhanced, while decreasing intracellular ATP attenuated the ability of proteasome inhibition to induce cell death. These data strongly suggest that endogenous ATP within the physiological concentration range can exert a negative impact on proteasome activities, allowing the cell to rapidly upregulate proteasome activity on ATP reduction under stress conditions.

Keywords: ATP; proteasome; regulation; apoptosis

Cell Research (2010) 20:1372-1385. doi:10.1038/cr.2010.123; published online 31 August 2010

\section{Introduction}

Intracellular protein degradation is mainly carried out by the autophagy-lysosome pathway and the ubiquitinproteasome system (UPS), which is ATP dependent [1-3]. The UPS is responsible for specific degradation of most

\footnotetext{
*These five authors contributed equally to this work. Correspondence: Jinbao Liu ${ }^{\mathrm{a}}$, Xuejun Wang ${ }^{\mathrm{b}}$

${ }^{\mathrm{a}}$ Tel: +86-20-81340720; Fax: +86-20-81340542

E-mail: liujinbao1@yahoo.com.cn

${ }^{\mathrm{b}} \mathrm{Tel}$ : +1-605-677-5132; Fax: +1-605-677-6381

E-mail: xuejun.wang@usd.edu

Author contributions: JL and XW conceived the study, analyzed data, and wrote the paper; other authors planned experiments and assisted in writing this paper or analyzing the data.

Received 26 February 2010; revised 8 June 2010; accepted 11 July 2010; published online 31 August 2010
}

intracellular normal and abnormal proteins. In general, UPS-mediated proteolysis includes two steps: ubiquitination of targeted protein molecules and degradation of the ubiquitinated proteins by the $26 \mathrm{~S}$ proteasome. The $26 \mathrm{~S}$ proteasome is assembled by the association of the $19 \mathrm{~S}$ regulatory particle with the $20 \mathrm{~S}$ proteolytic core particle in an ATP-dependent manner [4, 5]. Besides promoting 26S assembly [5], ATP is also essential to both the ubiquitination reaction and the functioning of $19 \mathrm{~S}$ proteasome, which deubiquitinates, unfolds, and channels the target protein into the proteolytic chamber of the $20 \mathrm{~S}$ core [6]. Additionally, the $20 \mathrm{~S}$ proteasome core seems to be able to degrade certain protein targets, such as ornithine decarboxylase and oxidized proteins, in an ATP- and ubiquitin-independent fashion [7, 8]. In the past several decades, exciting progress has been made in understanding the general ubiquitination process and 
how the proteasome works in general $[4,9]$. It is emerging that posttranslational modifications of proteasome subunits may have significant impacts on proteasome function [10]. However, our understanding on how the proteasome activity is regulated timely to meet the dynamic demand of cell functions and to harmonize with energy metabolism in the cell remains quite rudimentary.

Intracellular ATP levels are generally in the low millimolar range [11-14], but ATP at a level within this range was shown to suppress proteasome peptidase activities in vitro $[15,16]$. Proteasome activities in cells facing energy challenge tend to elevate $[17,18]$. These observations prompted us to hypothesize that proteasome activities in the cell are geared in a relatively lower state under physiological ATP conditions. Hence, we carried out a series of experiments to test this hypothesis. Our results strongly support this hypothesis, revealing a previously underappreciated mechanism by which the cell reserves its proteasome function at the baseline and rapidly mobilizes the reserve on a moderate reduction of ATP. This mechanism not only could readily explain a wide variety of (patho)physiological processes but also may potentially be captivated to develop novel strategies to treat lifethreatening diseases by altering ATP levels in the cell to manipulate proteasome function.

\section{Results}

ATP exerts bidirectional regulations on 265 proteasome activities in vitro

The homeostatic level of intracellular ATP ranges generally from 0.5 to $5 \mathrm{mM}$, depending on cell types [11-14]. To test the direct effect of the physiological level of ATP on proteasome function, we first examined the in vitro peptidase activities of purified 26S proteasomes in buffers containing various concentrations of ATP. We found that ATP at a concentration lower than $50 \mu \mathrm{M}$ stimulated the chymotrypsin (CT)-like activity of purified $26 \mathrm{~S}$ proteasomes; however, at a concentration higher than $\sim 100 \mu \mathrm{M}$, additional ATP did not further stimulate the proteasome, but rather showed a dose-dependent suppression on the proteasome activity (Figure 1). This is consistent with previous reports using the crude protein extract of heart tissue as the proteasome donor and purified $26 \mathrm{~S}$ proteasomes $[15$, 16]. These in vitro results suggest that ATP at a physiological concentration beyond a minimum level required for $26 \mathrm{~S}$ proteasome assembly and function may very likely yield an inhibitory effect on proteasome proteolytic activity in the cell and, therefore, decreasing ATP within a physiologically tolerable range will release the inhibition and thereby rapidly increase proteasome proteolytic activities. Our further experimentation, as shown below,

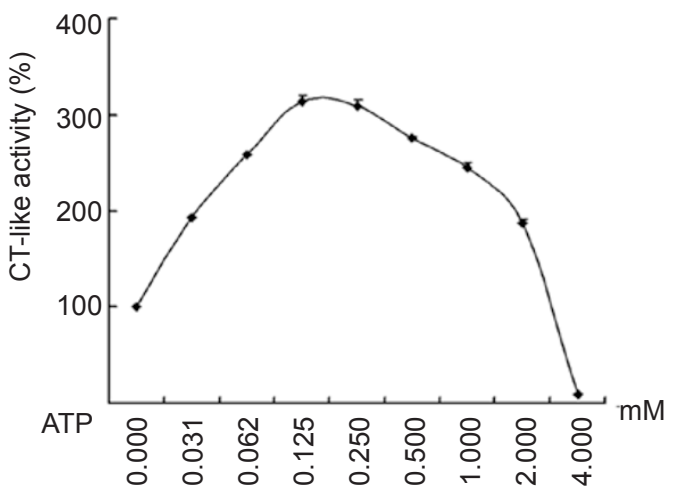

Figure 1 ATP bidirectionally modulates in vitro $26 \mathrm{~S}$ proteasome peptidase activities. Purified $26 \mathrm{~S}$ proteasomes were treated with ATP at the indicated doses in a Tris reaction system $(\mathrm{pH} 7.4)$. The chymotrypsin-like (CT-like) peptidase activity was measured using specific synthetic fluorogenic substrates.

demonstrates that this is indeed the case in the cell.

Bidirectional regulations of proteasome proteolysis by ATP in vivo

To test whether ATP has the bidirectional effects on $26 \mathrm{~S}$ proteasomes in vivo, we performed experiments in cultured cells in which ATP production was manipulated and proteasome proteolytic function assessed. Cellular ATP mainly comes from oxidative phosphorylation and glycolysis. Therefore, oligomycin, a specific inhibitor of oxidative phosphorylation, was utilized to block ATP production from substrate aerobic oxidation and glucose withdrawal, or 2-deoxyglucose (2DG) was employed to reduce glycolysis-dependent ATP production. In K562 and P388 leukemic cells cultured in the D-glucosecontaining media, oligomycin moderately decreased the levels of intracellular ATP (Figure 2A and 2E), but significantly reduced polyubiquitinated proteins and other proteasome substrates including $\mathrm{p} 27$ and $\mathrm{I}-\kappa \mathrm{B} \alpha$ in a dose-dependent manner (Figure 2B and 2F). While in the glucose-free medium or the L-glucose-containing medium (L-glucose cannot be used to generate ATP), oligomycin quickly depleted intracellular ATP (Figure $2 \mathrm{~A}$ and $2 \mathrm{E}$ ) and dose-dependently increased the levels of polyubiquitinated proteins, p27 and I- $\mathrm{kB} \alpha$ (Figure 2B and $2 \mathrm{~F}$ ). When cultured in glucose-free medium for $2 \mathrm{~h}$, the ATP concentration in K562 cells dropped by $\sim 50 \%$, compared with those cultured in the medium containing $2 \mathrm{~g} / \mathrm{l}$ D-glucose (Figure 2C). Addition of D-glucose to glucose-free medium efficiently increased both the levels of cellular ATP (Figure 2C) and the polyubiquitinated proteins (Figure 2D). Similar results were also observed in cultured P388 cells (Figure 2G and 2H). These results 
A

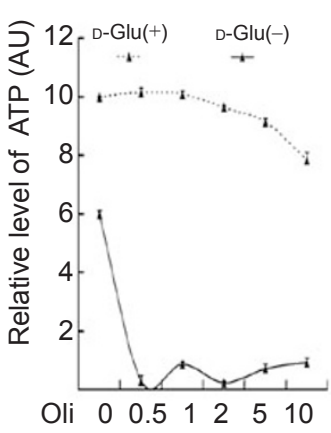

$E$

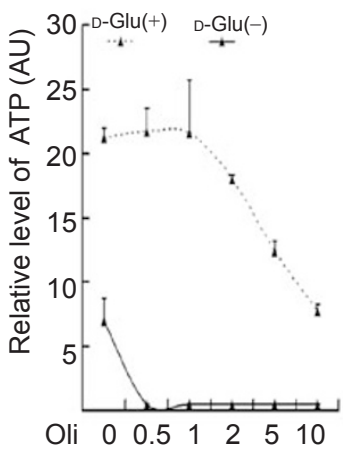

B

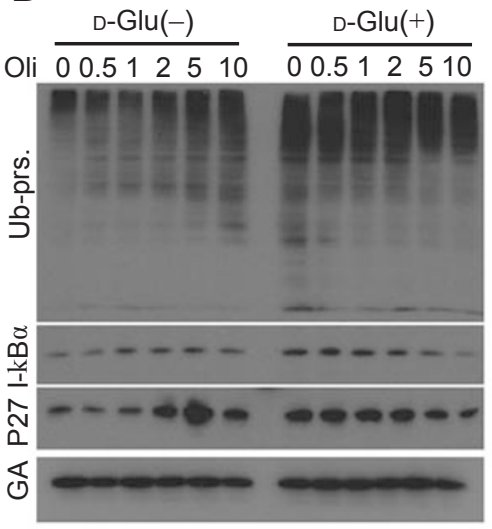

$\mathrm{F}$

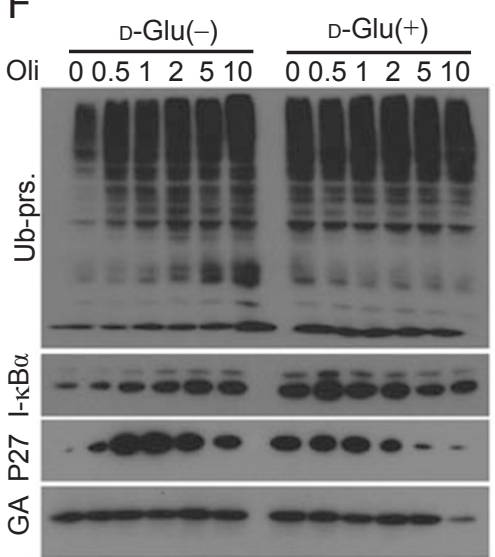

C

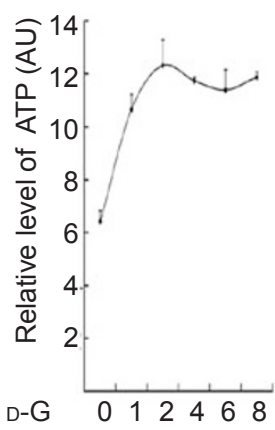

G

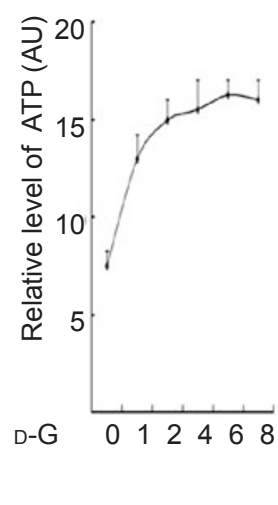

D

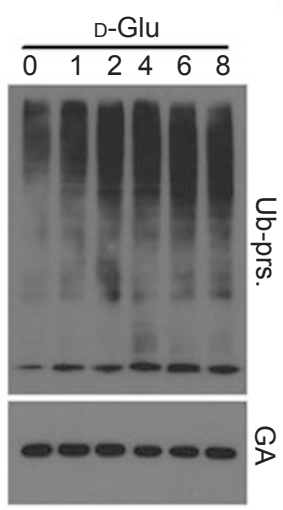

$\mathrm{H}$

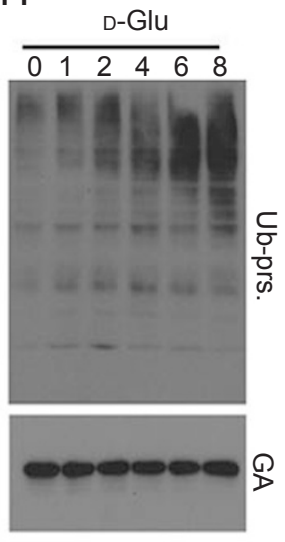

Figure 2 Severe and moderate reduction of intracellular ATP induces bidirectional changes of proteasome substrates in cultured cells. (A, B) Oligomycin (Oli) induced changes in the ATP levels (A, mean+SD) and changes in the protein levels of ubiquitinated proteins (Ub-prs.), p27, and I-KB $\alpha(B)$ in K562 cells that were cultured in D-glucose (D-Glu)-containing and D-Glufree media. The ATP levels were measured with the cell lysates collected at $6 \mathrm{~h}$ after Oli treatment at the indicated doses $(\mu \mathrm{g} /$ $\mathrm{ml})$. ATP levels in the equal number of cells are presented. The protein levels (B) were analyzed using western blotting, with the cell lysates collected at $24 \mathrm{~h}$ after Oli treatment (B). The same membrane was re-probed for GAPDH (GA) as loading controls. Representative images are shown. (C, D) Relative ATP levels (C, mean+SD) and representative images of western blotting analysis for Ub-prs in K562 cells that were treated with D-Glu at the indicated doses (g/l) for 2 h (C) and 6 h (D), respectively. (E, F) Relative ATP levels (E) and representative western blotting images of Ub-prs (F) in P388 cells that were cultured in the 1640 RPMI medium and treated with indicated doses of Oli for $2 \mathrm{~h}$ (E) and $6 \mathrm{~h}$ (F), respectively. D-Glu (+) stands for D-glucose (2 g/l); D-Glu (-) stands for D-glucose-free. (G, H) Relative ATP levels (G) and representative images of western blotting analysis for Ub-prs (H) in P388 cells that were treated with D-glucose at the indicated doses for $2 \mathrm{~h}(\mathbf{G})$ and $6 \mathrm{~h}(\mathbf{H})$, respectively.

suggest that altering intracellular ATP levels seems to produce bidirectional effects on proteasome proteolytic function in the cell, consistent with the in vitro results (Figure 1).

To further demonstrate that the observed regulation of intracellular ATP levels on proteasome proteolytic function has a functional consequence on the degradation of a proteasome-specific full-length protein substrate, we created clonal SH-SY5Y cells stably expressing a degron $\mathrm{CL} 1$-fused green fluorescence protein $(\mathrm{GFPu})$, referred to as GFPu-5Y cells. The degradation of GFPu depends on the UPS $[19,20]$. This is further verified by the ability of proteasome inhibition to increase GFPu protein levels in the GFPu stably transfected cells (Figure 3A). With $2.5 \mu \mathrm{g} / \mathrm{ml}$ oligomycin treatment, the ATP levels in GFPu$5 \mathrm{Y}$ cells were time-dependently decreased (Figure 3B). Western blotting analyses revealed that GFPu protein levels in these cells were significantly decreased at $1 \mathrm{~h}$ and $3 \mathrm{~h}$, returned to the control level at $6 \mathrm{~h}$, and became significantly increased at $12 \mathrm{~h}$ after oligomycin treatment 
A

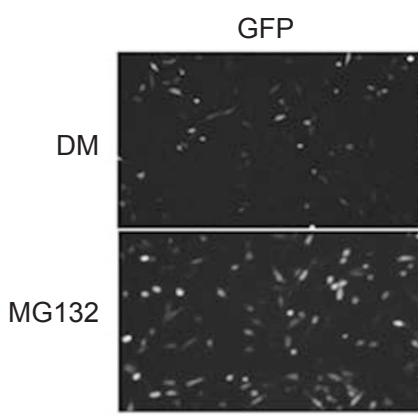

C

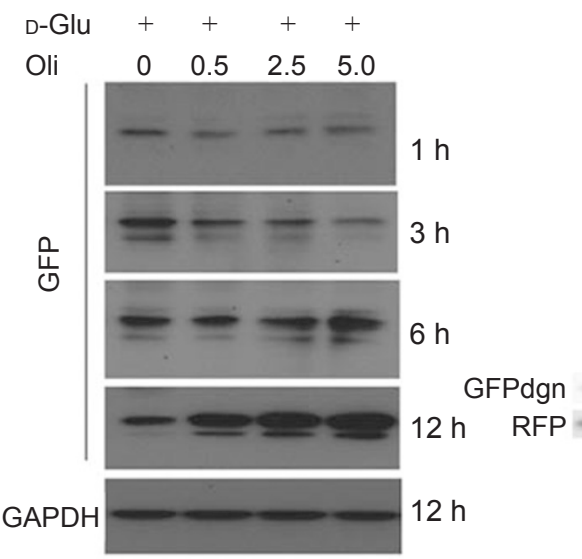

B

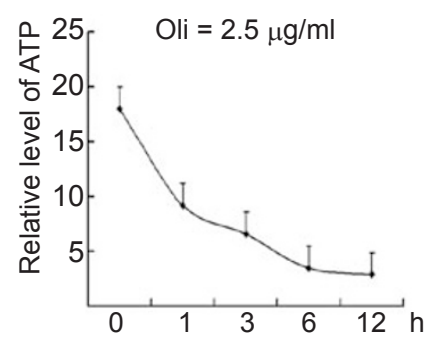

E ㄷㄷㄷำ

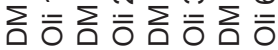
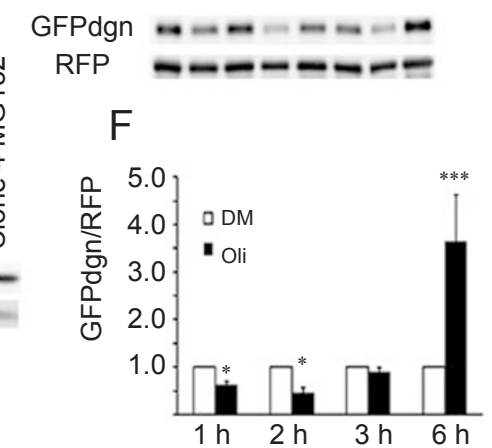

Figure 3 Changes of intracellular ATP bidirectionally alter the stability of GFPu and GFPdgn in cultured cells. (A) MG132 accumulated GFPu in GFPu-5Y cells (a clonal SH-SY5Y cell line stably transfected with GFPu, a surrogate UPS substrate). DM: DMSO. (B) The time course of oligomycin (Oli, $2.5 \mu \mathrm{g} / \mathrm{ml}$ ) induced decreases of ATP levels in GFPu-5Y cells cultured in the glucose-containing medium. (C) Temporal monitoring of dose-response of Oli treatment on the GFPu protein levels in GFPu-5Y cells cultured in the glucose-containing medium. (D) Representative western blotting images show that MG132 increased GFPdgn but not RFP protein levels in the GFPdgn/RFP stably transfected HEK293 cells. (E, F) Temporal changes in GFPdgn and RFP in the GFPdgn/RFP double-stably transfected HEK293 cells treated with Oli $(1.0 \mu \mathrm{g} / \mathrm{ml})$ in the glucose-free culture medium. A representative set of images of western blotting for GFPdgn and RFP (E) and a summary of GFPdgn/RFP ratios derived from six independent repeats $(\mathbf{F})$ are presented. ${ }^{*} P<0.05,{ }^{* * *} P<0.001$ vs the same time point vehicle control (DMSO) treatment group.

(Figure 3C). The bidirectional nature of the temporal changes in GFPu protein levels after oligomycin treatment corroborates very well with the in vitro bidirectional effects of ATP on the proteasome peptidase activity.

Reduction of ATP may inhibit protein synthesis, which can also cause a decrease in GFPu protein levels. To further demonstrate that changes in UPS-mediated protein degradation accounts for the observed GFPu changes, we next created clonal HEK293 cell lines with stable double transfection of GFPdgn and a red fluorescence protein (RFP). Derived from GFPu, GFPdgn is also a validated substrate for the UPS [21]. The RFP is not a specific substrate for the UPS and this is verified by the absence of a change in RFP levels in the face of a marked ac- cumulation of GFPdgn in the GFPdgn/RFP-stable cells on proteasome inhibition (Figure 3D). The RFP expression vector was constructed similar to that of GFPdgn so that any potential changes in general transcription and translation induced by an ATP manipulation would have a similar effect on both GFPdgn and RFP in the GFPdgn/ RFP-stable cell lines. Therefore, the use of the GFPdgn/ RFP protein ratio to monitor UPS function is more accurate than GFPdgn, as the impact from potential changes in protein synthesis on GFPdgn protein levels is now controlled for. As expected, in the absence of D-glucose in the culture medium, oligomycin treatment exerted a typical bidirectional influence on the GFPdgn/RFP ratio. The GFPdgn/RFP ratio was significantly decreased at 1 
and $2 \mathrm{~h}$, returned to nearly the control level at $3 \mathrm{~h}$, and significantly increased at $6 \mathrm{~h}$ after the oligomycin treatment $(1 \mu \mathrm{M}$; Figure $3 \mathrm{E}$ and $3 \mathrm{~F})$.

Taken together, the findings from the cell culture experiments recapitulate nicely the in vitro findings described earlier (Figure 1) and previously reported by others $[15,16]$, strongly supporting a bidirectional regulation of ATP over proteasome function in the cell. In the activation arm, a below-a-threshold ATP concentration is positively correlated with proteasome function; in the inhibition arm, however, a beyond-the-threshold ATP concentration is negatively correlated with proteasome function. The threshold was roughly $50-100 \mu \mathrm{M}$ under the in vitro condition used in the present study (Figure 1). The threshold in intact cells is not exactly defined at this time, but our data clearly reveal that it is substantially lower than the normal ATP level in the cell. The activation arm is consistent with what is already known [5, 6, 22], while the inhibition arm had not been well demonstrated in the cell, although it had been recently implicated by a few studies $[15,16]$.

ATP levels determine the efficacy of proteasome inhibition to cause cell death

It is well known that proteasome inhibition can induce apoptosis and/or necrosis. On the basis of the parabolic feature of the dose-response curve of ATP modulating the $26 \mathrm{~S}$ proteasome activity, we hypothesize that a higher intracellular ATP level within 'the inhibition arm' would make proteasome inhibitors more effective in inducing cell death. ATP concentration of cells cultured in the D-glucose-containing medium is considered within the physiological range, because this medium provides the optimal condition for cell culture. Several ATP states were modeled and the cell death induced by the proteasome inhibitors MG132 or MG262 was temporally assessed.

First, as shown in Figure 2A and 2C, the ATP level in $\mathrm{K} 562$ cells cultured in the glucose-free medium was $\sim 50 \%$ of that in the D-glucose medium. Annexin V-propidium iodide (PI) double staining followed by flow cytometry revealed that MG262 (62.5 nM-1.0 $\mu \mathrm{M}$, Figure 4A and 4B) or MG132 (1-20 $\mu \mathrm{M}$, Figure 4C) in a range of doses induced significantly more cell death in the D-glucosecontaining medium than in the glucose-free medium. This is further demonstrated by imaging the membrane permeability of living cells in PI-containing culture medium (Figure 4D).

Second, oligomycin decreased ATP content by $\sim 20 \%$ in $\mathrm{K} 562$ cells cultured in normal D-glucose ( $2 \mathrm{~g} / \mathrm{l})$ containing medium (Figure 2A). Under this condition, oligomycin significantly attenuated the ability of MG262 to induce cell death (Figure 4E and 4G) and markedly shifted MG-132 induced apoptosis from the late stage to the early stage (Figure 4E and 4F). To further compare the effects of three different levels of intracellular ATP on proteasome inhibition-induced cell death, the ATP concentration was set at $\sim 100 \%, 80 \%$, or $50 \%$ of the normal level, respectively, by culturing the cells in the D-glucose medium, the D-glucose+oligomycin medium, or the glucose-free medium. By temporally monitoring PI-positive nuclear staining of live cells cultured in these conditions, we confirmed that the effectiveness of MG132 $(5 \mu \mathrm{M})$ to induce cell death is time dependent, but the effectiveness decreased dose-dependently as the ATP was forced to decrease from $100 \%$ to $80 \%$ and $50 \%$ of the normal level (Figure 5).

Unlike D-glucose, L-glucose cannot be utilized by the cell to produce ATP. To control for the potential nonATP-increasing effects of D-glucose, the impact of D-glucose and L-glucose on proteasome inhibition-induced cell death was compared in K562 cells. D-glucose, but not L-glucose at the equivalent dose, significantly enhanced MG262- or MG132-induced cell death, as revealed by the cell death assay using the flow cytometry after the Annexin V-PI double staining (Figure 6A-6C), as well as the detection of lactate dehydrogenase $(\mathrm{LDH})$ release from the cell to the culture medium (Figure 6D). The cell death data were also confirmed by additional morphological analyses for chromosome condensation and nuclear fragmentation (Figure 6E and 6F), and characteristic cell shape changes (Figure 6G). These additional control experiments confirm that the enhancing effect of D-glucose on the induction of cell death by proteasome inhibition is only attributable to the increase of ATP production.

As glycolysis plays a major role in ATP generation, we next used 2DG in K562 cells to inhibit glycolysis as an alternative way to decrease ATP production and investigated its effect on proteasome inhibition-induced cell death. As shown in Figure 7A, 2DG significantly decreased ATP concentration and, as expected, significantly attenuated MG132-induced cell death (Figure 7B and 7C). Essentially, the same results were also obtained when a similar experiment was performed using a human lung cancer cell line (H460), in which a moderate inhibition of ATP generation by 2DG significantly attenuated MG132-induced LDH release and cell death (Figure 7D$7 \mathrm{~F})$.

Notably, the increased resistance to proteasome inhibitor-induced cell death by a moderate reduction of intracellular ATP is time dependent. It was only observed in the initial period of the time after the administration of a proteasome inhibitor. Comparable cell death occurred eventually in all groups treated with the proteasome 
A
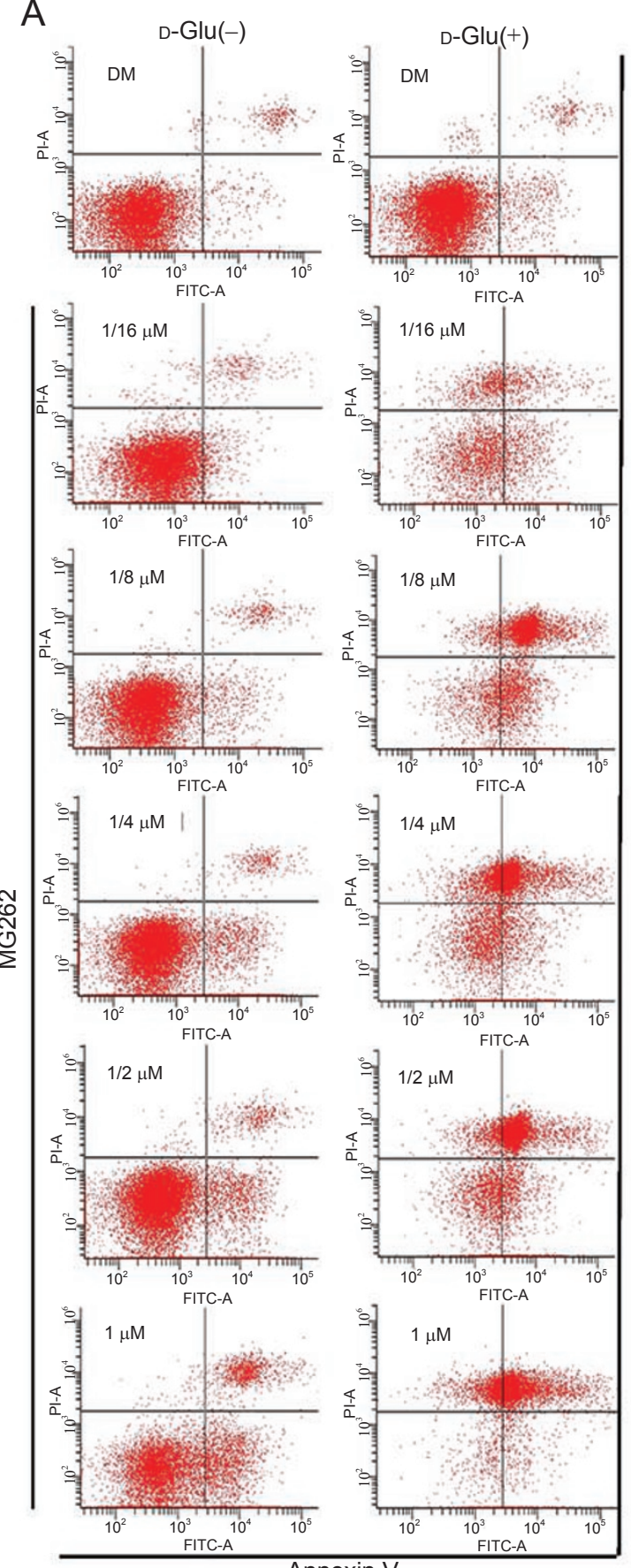

C
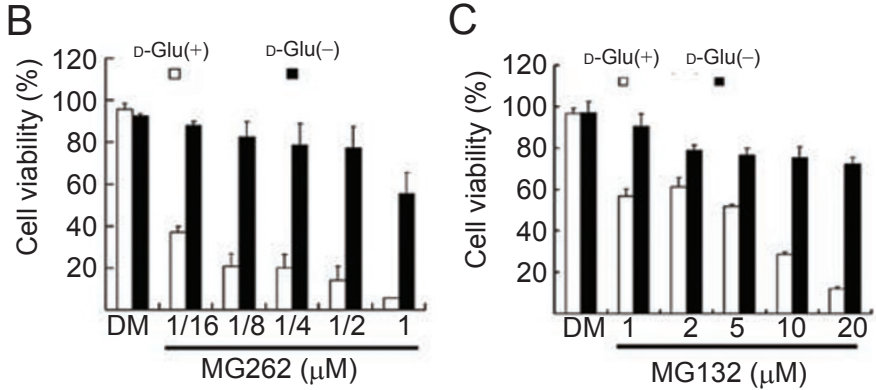

D-Glu(+)

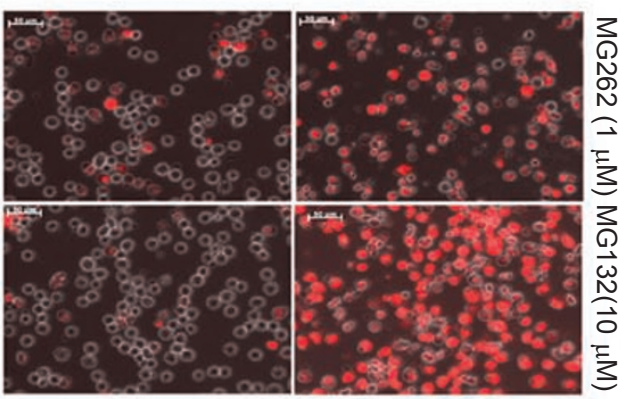

E
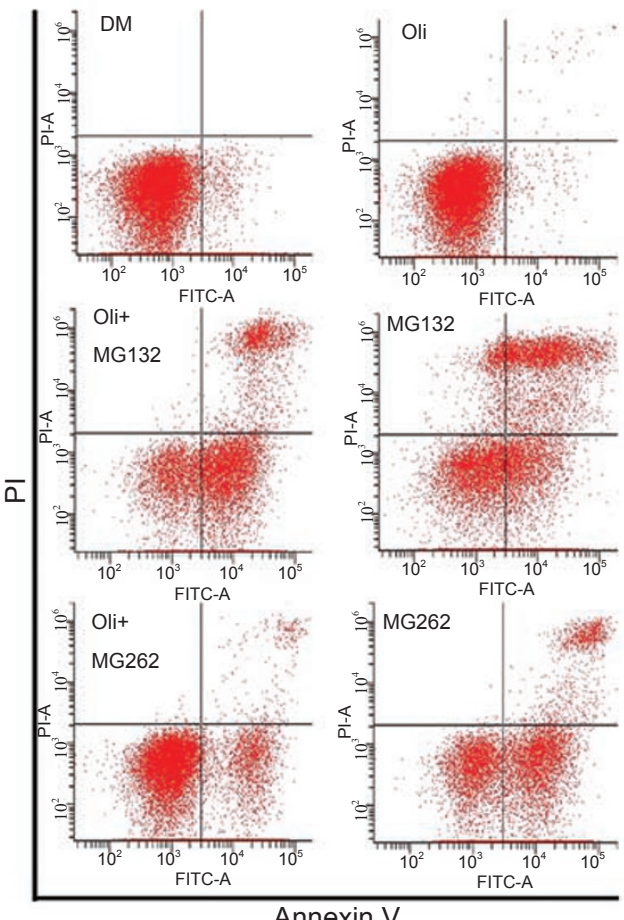

F
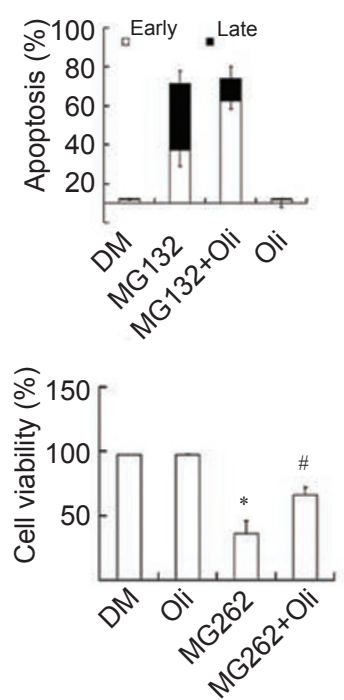
Figure 4 Intracellular ATP concentration determines the efficacy of proteasome inhibition to induce cell death. (A) Cell viability assays by flow cytometry. K562 cells were cultured in the 1640 RPMI glucose-free medium with or without the addition of D-glucose (D-Glu, $2 \mathrm{~g} / \mathrm{ll}$ ). After treatment with MG262 at the indicated doses for $36 \mathrm{~h}$, the cells were collected and subjected to Annexin V-FITC/propidium iodide (PI) double staining for flow cytometry. The lower right quadrant (Annexin V-FITC+/PI-) was considered as early-stage apoptotic cells, the upper right quadrant (Annexin V-FITC+/PI+) was considered late-stage apoptotic cells, and the upper left quadrant (Annexin V-FITC-/PI+) was considered as necrotic cells. (B) Summaries of changes in the percentage of viable cells (that is, percentage of cells in the lower left quadrant), as assessed in the experiments shown in panel A. (C) Removal of glucose from the culture medium increases the resistance of K562 cells to MG132-induced cell death. K562 cells were treated with MG132 at the indicated doses for $24 \mathrm{~h}$ in the presence or absence of D-glucose $(2 \mathrm{~g} / \mathrm{l})$ in the 1640 RPMI medium. Cell viability was assayed by flow cytometry, as described in panel A. (D) Representative micrographs of live cultured cells with in situ staining for cell death. K562 cells were treated with MG132 (10 $\mu \mathrm{M})$ or MG262 (1 $\mu \mathrm{M})$ for $24 \mathrm{~h}$ in the absence or presence of D-glucose in the culture medium. PI was added to the medium and 15 min later, the cells on the culture dish were directly imaged for both PI-positive staining (red) and the phase contrast using an inverted fluorescence microscope. The merged images between red fluorescence and the phase-contrast images are shown. Scale bar $=50 \mu \mathrm{m}$. (E) K562 cells were treated with MG132 $(5 \mu \mathrm{M})$ or MG262 $(0.5 \mu \mathrm{M})$ for $12 \mathrm{~h}$ in the $1640 \mathrm{RPMI}$ D-glucose medium in the absence or presence of oligomycin (Oli, $0.5 \mu \mathrm{g} / \mathrm{ml}$ ), followed by Annexin V-PI double staining for cell death assay via flow cytometry. A representative image of each group from three independent repeats is shown. (F) A summary of the incidence of the early and late apoptosis in the groups treated with MG132, as shown in E. Oli cotreatment delayed the induction of apoptosis by MG132. Mean+SD, $n=3$. (G) A summary of percentage viable cells treated by MG262 as shown in $\mathrm{E}$. Mean+SD, $\mathrm{n}=3 . * P<0.01$, vs $\mathrm{DM}$ control; ${ }^{\#} P<0.01$ vs MG262 treatment.

inhibitor when they were observed for sufficiently long time (data not shown). In other words, the reduction of ATP only significantly delayed proteasome inhibitioninduced cell death.

All the results reported in this paper support a conclusion that a decrease of intracellular ATP concentration in the inhibition arm attenuates proteasome inhibitioninduced cell death at these early time points tested. These results, therefore, lend additional support to the hypothesis that physiological levels of ATP negatively regulate proteasome function.

\section{Discussion}

It is well known that the $26 \mathrm{~S}$ proteasome is an ATPdependent multimeric protease in the cell. Through both in vitro and cell culture experiments, the present study has demonstrated that intracellular ATP levels beyond a threshold, but well within the homeostatic range, are negatively correlated to proteasome proteolytic activities, and intracellular ATP below a threshold is positively associated with proteasome activities. This helps unveil that ATP is a critical small molecule that may regulate proteasome function in the cell in two opposing directions, depending on its levels. This contention challenges the traditional dogma on ATP-mediated regulation of the proteasome function. As elaborated below, this new revelation of the effect of changing ATP levels on proteasome function is of potentially high significance and may potentially be exploited to design new therapeutic strategies to combat a variety of diseases, including some of the life-threatening ones.
First, the findings of our study help expand current understanding on the regulation of proteasome by intracellular ATP. The traditional view has been that ATP is required for and stimulates the assembly and functioning of the $26 \mathrm{~S}$ proteasome. Our study shows that this view is still true but represents only half of the picture, only the activation arm. We provide additional evidence here, helping reveal the other half of the picture, the inhibition arm, in which ATP at a level beyond a threshold appears to negatively impact the proteasome function in the cell. The threshold is likely the minimum ATP concentration required for $26 \mathrm{~S}$ proteasome assembly and the UPS to function in the cell. According to in vitro assessments (Figure 1), the threshold is likely in the $10-100 \mu \mathrm{M}$ range, which is at least one order of magnitude lower than the normal intracellular ATP level that is usually in the low $\mathrm{mM}$ range [11-14]. Therefore, the basal level of ATP constitutively exerts a negative regulatory effect on proteasome function in the cell, serving likely as a layer of safeguard for the proteasome reserve. The existence of the inhibition arm of ATP-mediated regulation over the proteasome conceivably allows the cell to rapidly upregulate its proteasome activities on ATP reduction, which often accompanies cellular stress. Indeed, gentle decreases of intracellular ATP by multiple means, such as the administration of oligomycin or 2DG, and glucose withdrawal were all able to significantly increase proteasome proteolytic function in the cell (Figures 2 and 3 ). The precise mechanism underlying the bidirectional regulation of ATP over proteasome activities remains to be further explored. Both direct and indirect effects from ATP may be involved. 


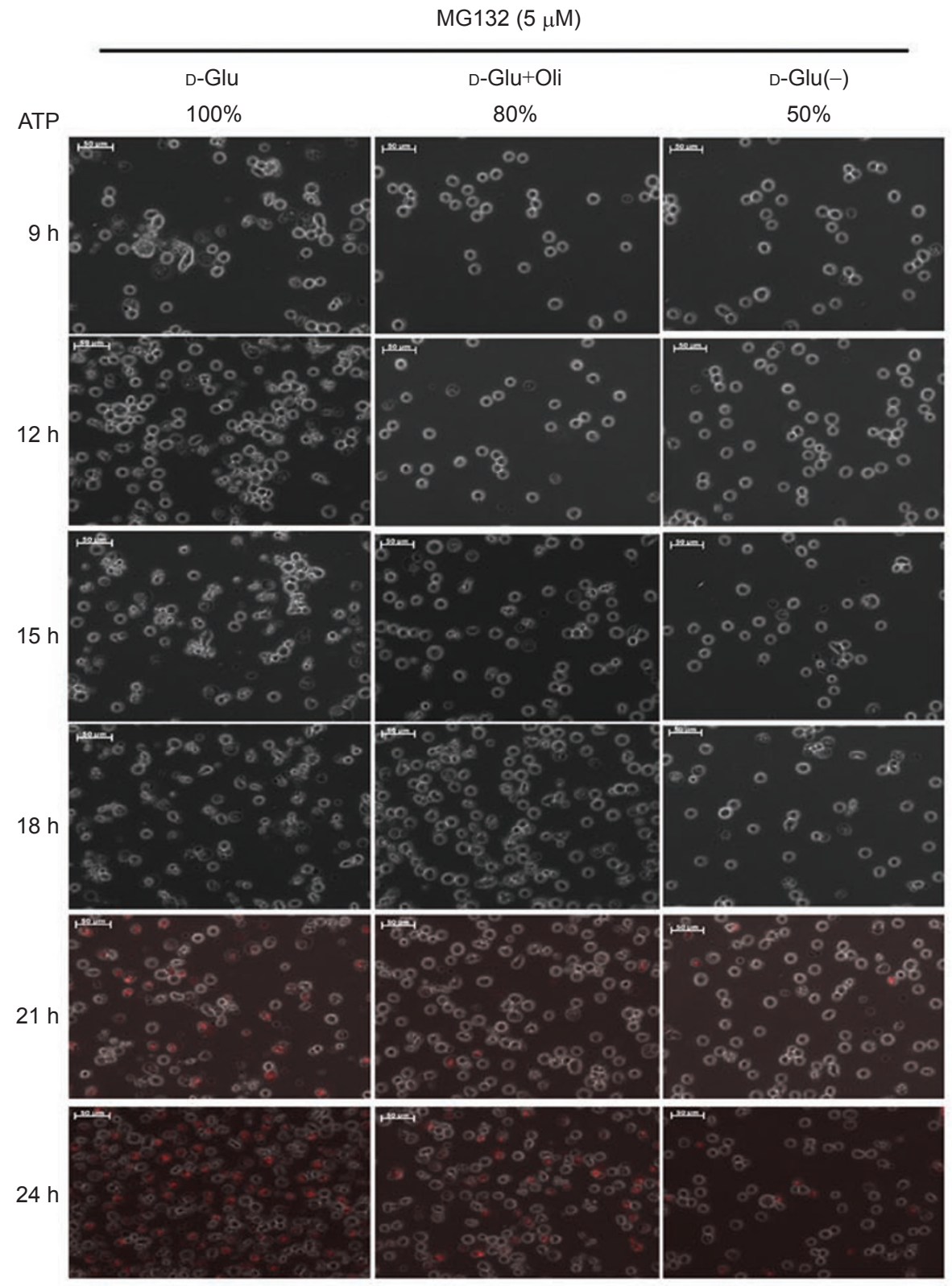

Figure 5 Temporal monitoring of cell death induced by proteasome inhibition in live cells cultured under various ATP states using propidium iodide (PI) staining and an inverted fluorescence microscope. In this setting, dead or dying cells were stained red by PI. Representative fluorescence micrographs of PI-stained living K562 cells taken at the indicated time points after MG132 $(5 \mu \mathrm{M})$ treatment are shown. The relative intracellular ATP concentrations were set at $\sim 100 \%, \sim 80 \%$, and $\sim 50 \%$ of the normal level, respectively, by culturing the cells in the D-glucose medium, the D-glucose+oligomycin medium, and the glucose-free medium. As the level of ATP decreased, the effectiveness of MG132 to induce cell death decreased. As the time of treatment went on, MG132-induced cell death increased in all the three ATP states.

In many pathological conditions, this suggested regulation appears to be in play as well. It was reported that proteasome peptidase activities were significantly increased in the heart under pressure overload, during which myocardial ATP levels were lower than normal [23]. Interestingly, pharmacological proteasome inhibi- tion markedly suppressed pressure overload cardiac hypertrophy [23]. Muscle wasting by proteasome activation has been confirmed in chronic occlusive pulmonary disease both in vitro and in vivo [17, 24, 25]. Severe acute hypoxia is seen in the acute respiratory distress syndrome (ARDS). Administration of proteasome inhibitors was 

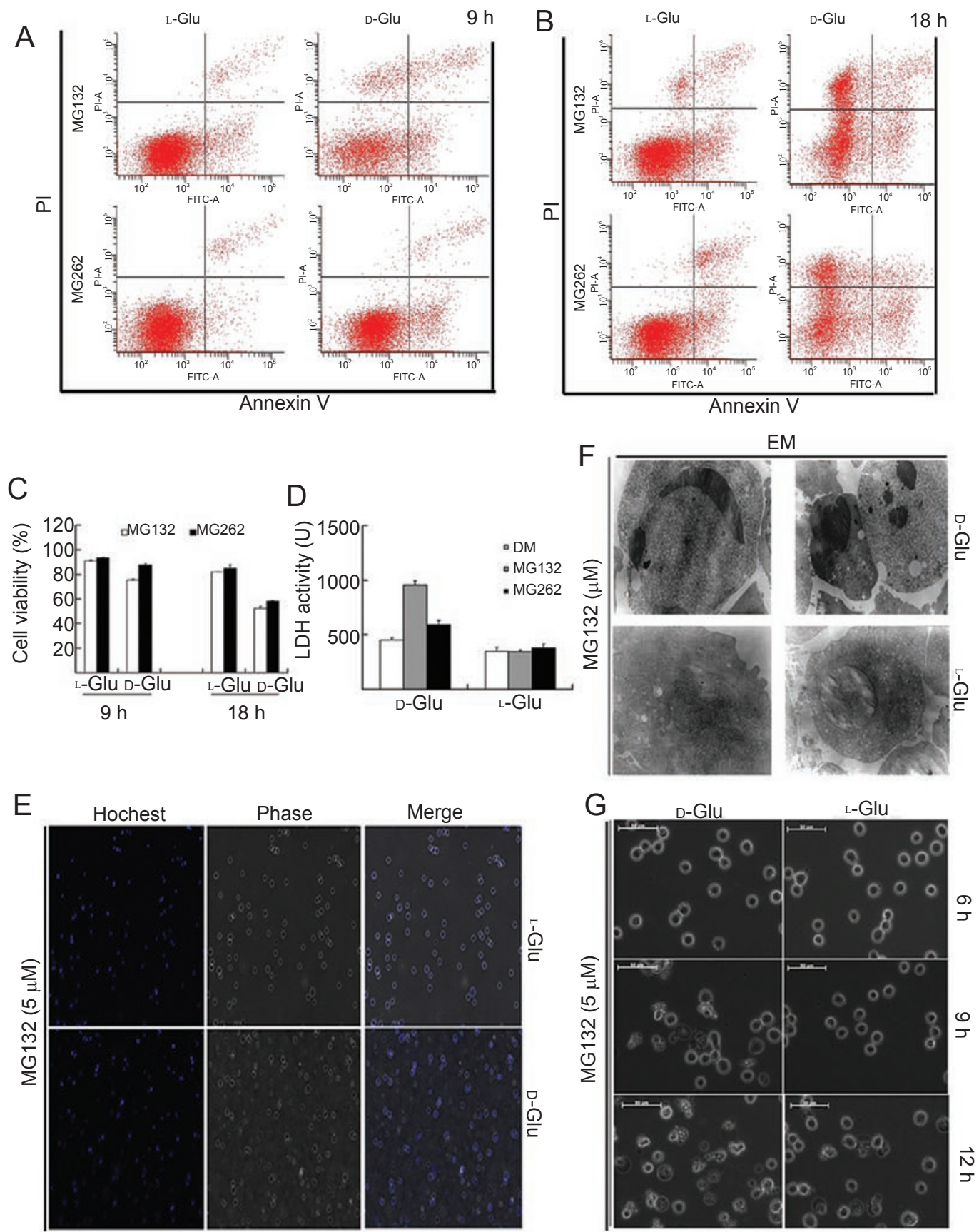

Figure 6 Comparison of the effects of L- and D-glucose (Glu) on proteasome inhibition-induced cell death in cultured K562 cells. K562 cells were treated with MG262 $(0.5 \mu \mathrm{M})$ or MG132 $(5 \mu \mathrm{M})$ for $9 \mathrm{~h}$ or $18 \mathrm{~h}$ in the 1640 RPMI medium with L-Glu (not usable by the cell to produce ATP) or D-Glu. Cell death was detected by Annexin V/PI double staining and flow cytometry. (A, B) Representative flow cytometric dot plots of the K562 cells undergoing the indicated treatment for $9 \mathrm{~h} \mathrm{(A)} \mathrm{or} 18 \mathrm{~h}$ (B). (C) A summary of cell viability data derived from experiments shown in A and B. (D) LDH activity in the culture medium derived from the experiments shown in B. (E) Nuclear morphology of K562 cells treated with M132 (5 $\mu \mathrm{M})$ in L-Glu or D-Glu containing medium for $12 \mathrm{~h}$. The nuclei of fixed cells stained blue by Hoechst. Phase contrast and blue fluorescence were imaged with epi-fluorescence microscopy. Chromatin condensation is more prevalent in the D-Glu group than the L-Glu group. (F) Representative transmission electronic microscopy (EM) micrographs of cells treated as described in A. Nuclear fragmentation and chromatin condensation were evident only in the D-Glu group. (G) As described in A, K562 cells were treated with MG132 $(5 \mu \mathrm{M})$, followed by recording the temporal morphological changes at 6,9 , and $12 \mathrm{~h}$. Representative phase-contrast images were shown. Cell disintegration and apoptotic bodies emerged much earlier and more frequently in the D-Glu group, compared with the L-Glu group after MG132 treatment. 
A

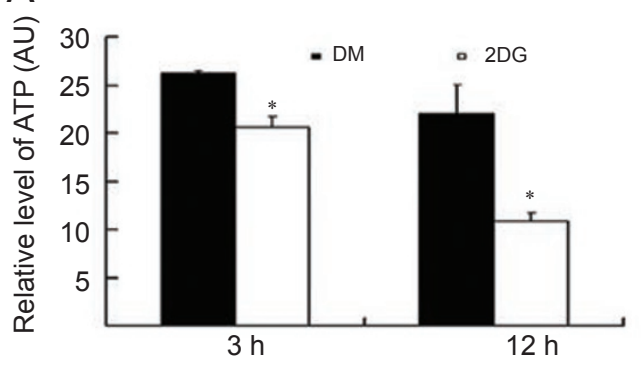

B

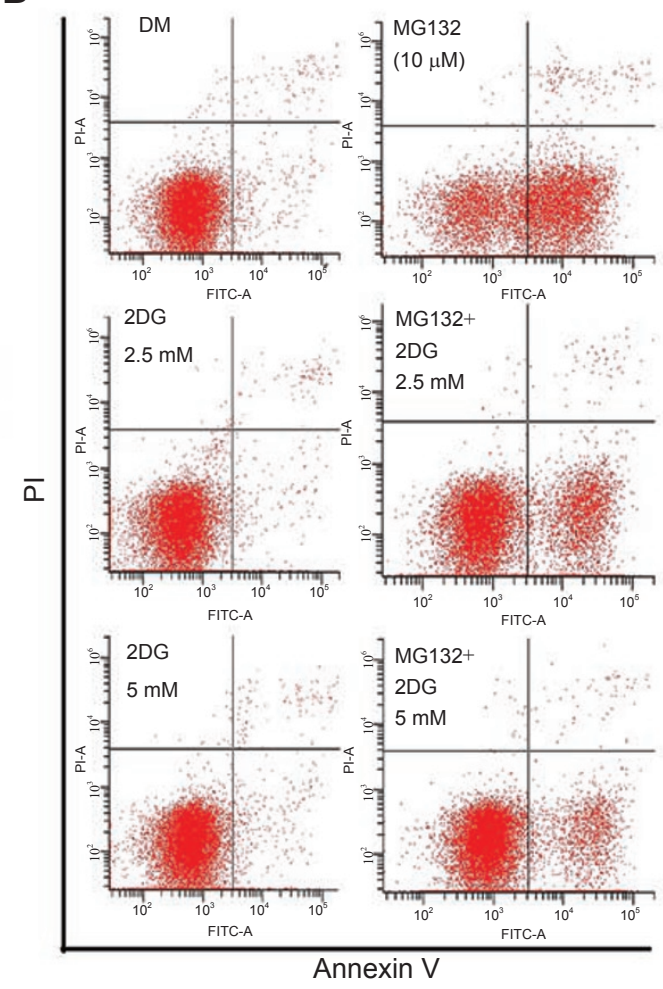

C

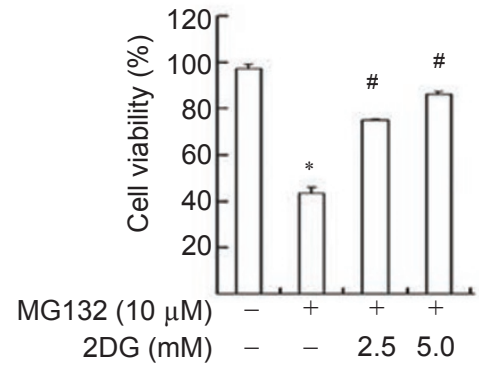

D

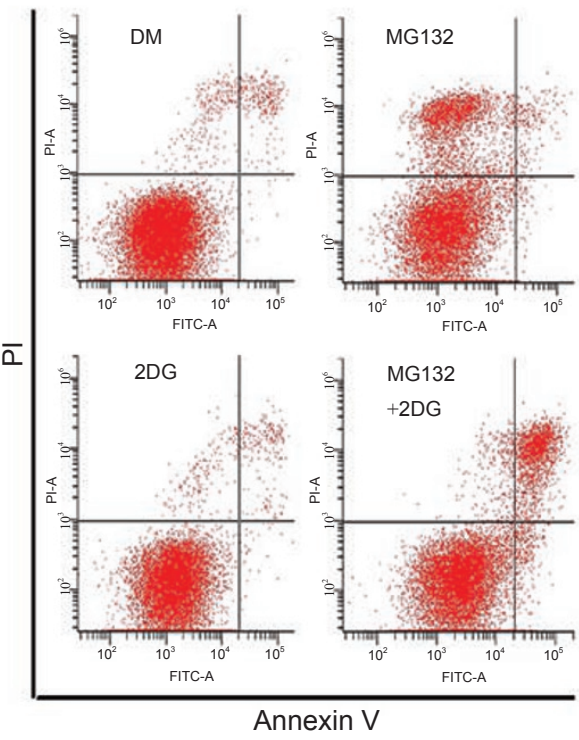

$E$

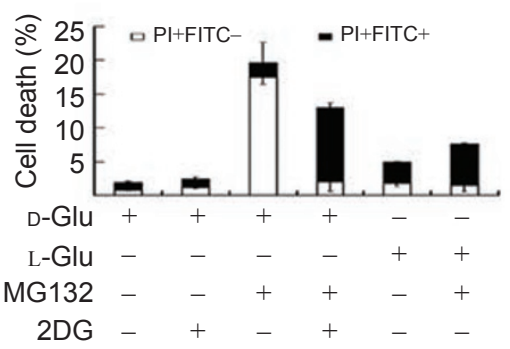

$\mathrm{F}$

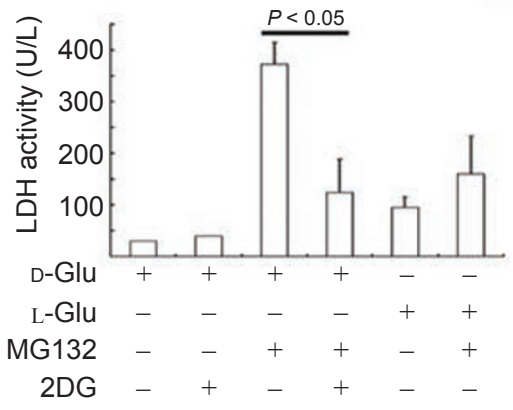

Figure 7 Inhibition of glycolysis by 2DG decreases intracellular ATP and rescues rescued MG132-induced cell death in K562 and $\mathrm{H} 460$ cells. (A) ATP levels in the lysate of K562 cells that were treated with 2DG (5 mM) or DMSO (DM) in the D-glucose 1640 RPMI medium for $3 \mathrm{~h}$ and $12 \mathrm{~h}$, were assayed using HPLC. (B) For cell death assay, cells were treated by MG132 $(10 \mu \mathrm{M})$ for $12 \mathrm{~h}$ in the presence of $2 \mathrm{DG}(2.5 \mathrm{mM}, 5 \mathrm{mM})$ in the RPMI 1640 medium. Cells were collected and labeled by Annexin $\mathrm{V}$ and $\mathrm{PI}$ for flow cytometry assessment of cell death. Representative images are shown. (C) A statistical summary of the data was illustrated. ${ }^{*} P<0.01$, compared with control treatment; ${ }^{\#} P<0.01$, compared with MG132 treatment alone. (D) H460 cells were treated with MG132 $(5 \mu \mathrm{M})$ or DMSO in the absence or presence of 2DG $(5 \mathrm{mM})$ for $12 \mathrm{~h}$, followed by Annexin V-PI staining for cell death assay. Representative images of cell death analyses by flow cytometry were shown. (E) Bar graph summarizing the cell death data illustrated in panel D. (F) LDH activities in the culture medium derived from the experiments illustrated in panel $\mathbf{D}$. 
shown to abrogate the hypoxia-induced severe pulmonary distress [26], suggesting that proteasome activation plays a pathogenic role in ARDS and decreased ATP production may be responsible as well. Another example is ischemia, in which decreases in ATP are common and again the proteasome is often activated during the early stage of ischemia, and proteasome inhibition often ameliorates ischemic injury [27]. These examples seem to share the sequela that decreases in intracellular ATP under the stress conditions are accompanied by proteasome activation, and the use of proteasome inhibitors is often beneficial in managing the stress. It was recently reported that prolonged glucose infusion in vivo could inhibit the proteasome function and decrease myofibrillar protein degradation [28]. It was further confirmed that glucose infusion, even at a relatively low rate, suppresses muscle protein breakdown in the early postoperative period via suppression of the UPS [29]. Direct ATP infusion increased liver energy status and slowed down weight loss in advanced lung cancer patients [30].

Second, the new contention strengthened by the present study may unveil a new mechanism by which the cell mobilizes its proteolytic capability in response to starvation. It is well documented that macroautophagy is activated on starvation to allow the cell to self-digest a portion of the cytoplasm for survival [31, 32]. Starvation inevitably decreases intracellular ATP; therefore, according to our new findings, proteasome-based proteolytic activity will also be increased at least at the initial stage of starvation when the ATP level is only moderately decreased. This is directly demonstrated by our data that glucose withdrawal decreases the level of proteasome substrates in cultured cells (Figures 2 and 3) and slows down cell death induced by proteasome inhibitors (Figure 4).

Third, the inhibition arm of the bidirectional regulation of ATP over the $26 \mathrm{~S}$ proteasome provides a rationale for manipulating intracellular ATP concentrations to alter proteasome function in the cell. The latter has tremendous therapeutic implications, because, for instance, modulating proteasome proteolytic function has been shown experimentally and/or clinically to be remarkably effective in mitigating a variety of pathological processes that are essential to the genesis and progression of a large set of life-threatening diseases such as cell proliferative diseases. To this end, we have demonstrated that increasing ATP production can synergize with pharmacological proteasome inhibitors to induce cell death of cultured cancer cells, whereas decreasing ATP production antagonizes proteasome inhibition induction of cell death (Figures 4-7).

Hypoxia is commonly found in solid tumors and upregulates a number of target genes involved in angiogenesis, anaerobic energy metabolism, cell survival, cell invasion, and drug resistance, thereby contributing to the progression of a more malignant phenotype and to the increased resistance to radiotherapy and chemotherapy [33]. On the basis of the bidirectional regulation of ATP over proteasome function, the reduction of ATP associated inevitably with hypoxia should activate the proteasome in the cancer tissue. Indeed, cancer tissue proteasome activities are generally significantly higher than the normal tissue from which the cancer originates. Moreover, it has been shown that administration of a proteasome inhibitor such as bortezomib can sensitize cancer cells to radiotherapy and chemotherapy [34-36]. Administration of these pharmacological inhibitors often unfortunately yields unintended severe adverse effects such as congestive heart failure [37]. Hence, increasing intracellular ATP may be a safe alternative measure to inhibit proteasomes in cancers, thereby sensitizing the cancer cells to radiotherapy and chemotherapy. Consistent with this postulate, intracellular ATP concentration has proven to be an important determinant for cell death [38-42].

\section{Materials and Methods}

\section{Materials}

ATP, Hochest 33258, and oligomycin (No. 04876) were purchased from Sigma-Aldrich (St. Louis, MO, USA). 2DG and L-glucose were purchased from Alfa Aesar (Karlsruhe, Germany); mouse monoclonal antibodies against GFP (clone 2), RFP, ubiquitin (P4D1), p27 (F-8), tubulin, and rabbit polyclonal antibodies against GAPDH (FL-335) and I- $\kappa \mathrm{B} \alpha(\mathrm{C}-15)$ were from Santa Cruz Biotechnology Inc (Santa Cruz, CA, USA). Enhanced chemiluminescence (ECL) reagents were from Amersham Biosciences (Piscataway, NJ, USA). Annexin V-FITC Apoptosis Detection Kit was from Keygen Company (Nanjing, China).

\section{Cell culture and ATP manipulation}

K562, P388, and NCI-H460 cells were purchased from the American Type Culture Collection (ATCC) and cultured in the RPMI1640 medium (GIBCO, USA) supplemented with 10\% fetal bovine serum (HyClone, Logan, UT, USA). SH-SY5Y cells and HEK293 cells were purchased from ATCC and cultured in DMEM medium with high glucose, supplemented with $10 \%$ fetal bovine serum (HyClone). Oligomycin, a classic inhibitor of F0F1-ATPase, was used to block ATP production from oxidative phosphorylation; withdrawal of D-glucose from the culture media was employed to reduce glucose-dependent ATP production; 2DG was used to block glycolysis-dependent ATP production.

\section{Peptidase activity assays}

The assays were performed as we have previously described $[43,44]$. A $20 \mu \mathrm{l}$ Tris- $\mathrm{HCl}$ buffer ( $\mathrm{pH} 7.4$ ) containing purified $26 \mathrm{~S}$ proteasomes (4 nM, Boston Biochem, Cambridge, MA, USA) was added to a total volume of $180 \mu \mathrm{l}$ Tris- $\mathrm{HCl}(\mathrm{pH} 7.4)$ reaction buffer containing the synthetic fluorogenic peptide Suc-LLVY-amin- 
omethylcoumarin (AMC) for the CT-like activity (final concentration $=25 \mu \mathrm{M}$, Calbiochem, USA). The reaction mixture was then incubated at $37{ }^{\circ} \mathrm{C}$ for $90 \mathrm{~min}$ and analyzed for the fluorescence intensity of the free AMC using a luminescence microplate reader (Varioskan Flash 3001, Thermo, USA). The excitation and emission wavelengths for measuring free AMC were $360 \mathrm{~nm}$ and 436 $\mathrm{nm}$, respectively.

\section{Creation of SH-SY5Y GFPu-stable cell lines}

SH-SY5Y cells were purchased originally from ATCC. GFPu, a GFP modified by carboxyl fusion of degron CL1, was previously proven to be a specific surrogate substrate for the UPS [19, 20]. A GFPu-expressing plasmid was used to transfect the SHSY5Y cells using a liposome-based transfection kit from Keygen Company (Nanjing, China). The transfected cells were selected for stable transfection using G418, as previously described [42]. The selected stably transfected clones were maintained in growth medium containing G418. These cells are referred to as GFPu-5Y cells in the main text.

\section{Creation of HEK293 GFPdgn/RFP-stable cell lines}

As previously described for generating the GFPu-2-stable cell lines [20], HEK293 cells from ATCC were cotransfected with pGFPdgn and pDSRed2-C1 plasmids using Lipofectamine 2000 (Invitrogen, Carlsbad, CA, USA). Derived from the original GFPu vector [19], the pGFPdgn vector was previously used to generate the GFPdgn transgenic mice and described therein [21]. The $\mathrm{pD}-$ SRed2-C1 encoding a RFP was purchased from Clontech (Mountain View, CA, USA).

\section{ATP content determination}

Equal number of cultured cells were collected and centrifuged for 5 min at $3000 \times g$ at $4{ }^{\circ} \mathrm{C}$, and the cell pellet was immediately frozen and stored in liquid nitrogen for subsequent ATP analyses. The frozen cells were resuspended in perchloric acid and lysed on ice. The lysates were centrifuged at 12000 r.p.m. for $10 \mathrm{~min}$ at $4{ }^{\circ} \mathrm{C}$. The supernatant was collected for analyzing ATP by using a reversed-phase C18 HPLC (LC-6AD, Shimadzu, Japan) assay, after the $\mathrm{pH}$ was adjusted to 7.4 [45]. $\mathrm{KH}_{2} \mathrm{PO}_{4}(180 \mathrm{mM})(5 \%$ methanol) was used as mobile phase $(\mathrm{pH} 6.25)$ running at $0.8 \mathrm{ml} /$ min. The assay was linear from 0.05 to $200 \mu \mathrm{g} / \mathrm{ml}$ for ATP with coefficient of determination $\left(R^{2}\right)>0.999$. Validation coefficients of variation for intra- and interday assays were $<1.5 \%$ and $5.1 \%$, respectively.

\section{Western blot analysis}

Western blotting was performed as previously described [43]. In brief, an equal amount of total protein extracts from cultured cells were fractionated by $12 \%$ SDS-PAGE and electrically transferred onto polyvinylidene difluoride (PVDF) membranes. Mouse, goat, or rabbit primary antibodies and horseradish peroxidaseconjugated appropriate secondary antibodies were used to detect the designated proteins. The bounded secondary antibodies on the PVDF membrane were reacted to the ECL detection reagents (Amersham Bioscience, Dübendorf, Switzerland) and exposed to X-ray films (Kodak, Japan) or directly imaged and digitalized using a BioRad VersaDoc 4000 imaging system and quantified by the Quantity One software (BioRad, CA, USA). The X-ray film expo- sure was scanned and digitalized using a high-resolution scanner. The density of desired bands was quantified with the Scion Image Analyzing software. For the quantification of total ubiquitinated proteins, all positive bands with a molecular weight greater than that of free $\mathrm{Ub}(7.6 \mathrm{kDa})$ were included.

\section{Cell death assay}

This was performed using Annexin V-FITC and PI double staining followed by flow cytometry, as described previously [43]. In brief, cultured K562 and H460 cells were harvested and washed with cold PBS and resuspended with the binding buffer, followed by Annexin V-FITC incubation for $15 \mathrm{~min}$ and PI staining for another 15 min at $4{ }^{\circ} \mathrm{C}$ in dark. The stained cells were analyzed with flow cytometry within $30 \mathrm{~min}$.

\section{LDH activity assay}

Release of LDH from the cytoplasm of cultured cells to the culture medium indicates a loss of plasma membrane integrity. Culture medium was collected from individual dishes or wells, and cell debris was removed by centrifugation. LDH activity in the collected medium was measured using the cytotoxicity detection kit (Keygen, Nanjing, China) by the reduction of lactate to pyruvate in the presence of NAD. The resultant NADH reduces tetrazolium to a red formazan product that is detectable at $490 \mathrm{~nm}$. Briefly, $100 \mu$ of reaction reagent was added to each well of a 96well plate containing $100 \mu \mathrm{l}$ of optimally titrated culture medium, and the mixture was incubated for $30 \mathrm{~min}$ at room temperature. Absorbance of the samples at $490 \mathrm{~nm}$ was read on a microplate reader (Sunrise, Tecan, Austria). The reference wavelength was $620 \mathrm{~nm}$. LDH activity was calculated according to the standard curve as $\mu \mathrm{mol} / \mathrm{l}$. Results from at least four separate experiments are presented.

\section{Morphological characterization of cell death}

K562 cells were treated as described. To monitor temporal changes in the incidence of cell death in the live culture condition, PI was added to the cell culture medium, and at the desired sequential time points, the cells in the culture dish were imaged with an inverted fluorescence microscope equipped with a digital camera (Axio Obsever Z1, Zeiss, Germany). PI is not able to enter the normal live cells, but the dying or dead cells lose their membrane integrity so that PI can enter their nucleus, bind to double-stranded DNA, and thereby positively stain the dying and dead cells. To observe the nuclear changes, K562 cells were collected, smeared on a slide, and stained with Hochest 33258 . The Hochest-stained cells were imaged with the inverted epi-fluorescence microscope.

For electron microscopy, the cells were washed and fixed overnight at $4{ }^{\circ} \mathrm{C}$ with $2 \%$ glutaraldehyde in $0.2 \mathrm{~mol} / 1$ sodium cacodylate buffer, dehydrated in a graded series of buffers, embedded in resin, and sectioned. The ultrathin sections were post-stained in uranyl acetate and lead citrate, and observed with a transmission electron microscope (JEM-100CXII, JEOL, Japan).

\section{Statistical methods}

Unless indicated otherwise, mean+SD are presented where applicable. Unpaired Student's $t$-test or one-way ANOVA is used where appropriate for determining statistic probabilities. $P$-value $<0.05$ is considered significant. 


\section{Acknowledgments}

This work was supported by the National High Technology Research and Development Program of China (Project 2006AA02Z4B5), the National Natural Science Foundation of China (Project 2010), and a Key Project (9251018201002) of Guangdong Province Natural Science Foundation (to JL). It was also supported in part by Grants HL072166, HL085629, and HL068936 of the NIH and an Established Investigator Award (0740025N) of the American Heart Association (to XW).

\section{References}

1 Hershko A, Ciechanover A. The ubiquitin system. Annu Rev Biochem 1998; 67:425-479.

2 Mizushima N, Levine B, Cuervo AM, Klionsky DJ. Autophagy fights disease through cellular self-digestion. Nature 2008; 451:1069-1075.

3 Korolchuk VI, Mansilla A, Menzies FM, Rubinsztein DC. Autophagy inhibition compromises degradation of ubiquitinproteasome pathway substrates. Mol Cell 2009; 33:517-527.

4 Besche HC, Peth A, Goldberg AL. Getting to first base in proteasome assembly. Cell 2009; 138:25-28.

5 Smith DM, Kafri G, Cheng Y, Ng D, Walz T, Goldberg AL. ATP binding to PAN or the 26S ATPases causes association with the 20S proteasome, gate opening, and translocation of unfolded proteins. Mol Cell 2005; 20:687-698.

6 Liu CW, Li X, Thompson D, et al. ATP binding and ATP hydrolysis play distinct roles in the function of $26 \mathrm{~S}$ proteasome. Mol Cell 2006; 24:39-50.

7 Asher G, Bercovich Z, Tsvetkov P, Shaul Y, Kahana C. 20S proteasomal degradation of ornithine decarboxylase is regulated by NQO1. Mol Cell 2005; 17:645-655.

8 Davies KJ. Degradation of oxidized proteins by the 20S proteasome. Biochimie 2001; 83:301-310.

9 Ravid T, Hochstrasser M. Diversity of degradation signals in the ubiquitin-proteasome system. Nat Rev Mol Cell Biol 2008; 9:679-690.

10 Zhang F, Hu Y, Huang P, Toleman CA, Paterson AJ, Kudlow JE. Proteasome function is regulated by cyclic AMP-dependent protein kinase through phosphorylation of Rpt6. J Biol Chem 2007; 282:22460-22471.

11 Gribble FM, Loussouarn G, Tucker SJ, Zhao C, Nichols CG, Ashcroft FM. A novel method for measurement of submembrane ATP concentration. J Biol Chem 2000; 275:3004630049.

12 Larcombe-McDouall J, Buttell N, Harrison N, Wray S. In vivo $\mathrm{pH}$ and metabolite changes during a single contraction in rat uterine smooth muscle. J Physiol 1999; 518:783-790.

13 Dragon S, Hille R, Gotz R, Baumann R. Adenosine 3':5'-cyclic monophosphate (cAMP)-inducible pyrimidine 5'-nucleotidase and pyrimidine nucleotide metabolism of chick embryonic erythrocytes. Blood 1998; 91:3052-8.

14 Kawashima $\mathrm{S}$. Inhibition of rat liver transglutaminase by nucleotides. Experientia 1991; 47:709-712.

15 Powell SR, Davies KJ, Divald A. Optimal determination of heart tissue 26S-proteasome activity requires maximal stimulating ATP concentrations. J Mol Cell Cardiol 2007; 42:265269.

16 Geng Q, Romero J, Saini V, et al. A subset of 26S proteaso- mes is activated at critically low ATP concentrations and contributes to myocardial injury during cold ischemia. Biochem Biophys Res 2009; 390:1136-1141.

17 Ottenheijm CA, Heunks LM, Li YP, et al. Activation of the ubiquitin-proteasome pathway in the diaphragm in chronic obstructive pulmonary disease. Am J Respir Crit Care Med 2006; 174:997-1002.

18 Pettersen EO, Juul NO, Ronning OW. Regulation of protein metabolism of human cells during and after acute hypoxia. Cancer Res 1986; 46:4346-4351.

19 Bence NF, Sampat RM, Kopito RR. Impairment of the ubiquitin-proteasome system by protein aggregation. Science 2001; 292:1552-1555.

20 Liu J, Chen Q, Huang W, et al. Impairment of the ubiquitinproteasome system in desminopathy mouse hearts. FASEB $J$ 2006; 20:362-364.

21 Kumarapeli AR, Horak KM, Glasford JW, et al. A novel transgenic mouse model reveals deregulation of the ubiquitinproteasome system in the heart by doxorubicin. FASEB $J$ 2005; 19:2051-2053.

22 Saeki Y, Tanaka K. Unlocking the proteasome door. Mol Cell 2007; 27:865-867.

23 Depre C, Wang Q, Yan L, et al. Activation of the cardiac proteasome during pressure overload promotes ventricular hypertrophy. Circulation 2006; 114:1821-1828.

24 Mitch WE, Goldberg AL. Mechanisms of muscle wasting. The role of the ubiquitin-proteasome pathway. $N$ Engl J Med 1996; 335:1897-1905.

25 Testelmans D, Crul T, Maes K, et al. Atrophy and hypertrophy signaling in the diaphragm of patients with COPD. Eur Respir J 2010; 35:549-556.

26 van Hees HW, Li YP, Ottenheijm CA, et al. Proteasome inhibition improves diaphragm function in congestive heart failure rats. Am J Physiol Lung Cell Mol Physiol 2008; 294:L1260-L1268.

27 Wojcik C, Di Napoli M. Ubiquitin-proteasome system and proteasome inhibition: new strategies in stroke therapy. Stroke 2004; 35:1506-1518.

28 Sadiq F, Crompton LA, Scaife JR, Lomax MA. Effect of prolonged intravenous glucose and essential amino acid infusion on nitrogen balance, muscle protein degradation and ubiquitin-conjugating enzyme gene expression in calves. Nutr Metab 2008; 5:5.

29 Mikura M, Yamaoka I, Doi M, et al. Glucose infusion suppresses surgery-induced muscle protein breakdown by inhibiting ubiquitin-proteasome pathway in rats. Anesthesiology 2009; 110:81-88.

30 Leij-Halfwerk S, Agteresch HJ, Sijens PE, Dagnelie PC. Adenosine triphosphate infusion increases liver energy status in advanced lung cancer patients: an in vivo $31 \mathrm{P}$ magnetic resonance spectroscopy study. Hepatology 2002; 35:421-424.

31 Mizushima N, Levine B, Cuervo AM, Klionsky DJ. Autophagy fights disease through cellular self-digestion. Nature 2008; 451:1069-1075.

32 Korolchuk VI, Mansilla A, Menzies FM, Rubinsztein DC. Autophagy inhibition compromises degradation of ubiquitinproteasome pathway substrates. Mol Cell 2009; 33:517-27.

33 Yeo EJ, Chun YS, Park JW. New anticancer strategies targeting HIF-1. Biochem Pharmacol 2004; 68:1061-1069. 
34 Hockel M, Vaupel P. Tumor hypoxia: definitions and current clinical, biologic, and molecular aspects. J Natl Cancer Inst 2001; 93:266-276.

35 Ogiso Y, Tomida A, Lei S, Omura S, Tsuruo T. Proteasome inhibition circumvents solid tumor resistance to topoisomerase II-directed drugs. Cancer Res 2000; 60:2429-2434.

36 Hideshima $\mathrm{T}$, Richardson $\mathrm{P}$, Chauhan $\mathrm{D}$, et al. The proteasome inhibitor PS-341 inhibits growth, induces apoptosis, and overcomes drug resistance in human multiple myeloma cells. Cancer Res 2001; 61:3071-3076.

37 Wang X, Su H, Ranek MJ. Protein quality control and degradation in cardiomyocytes. J Mol Cell Cardiol 2008; 45:11-27.

38 Eguchi Y, Shimizu S, Tsujimoto Y. Intracellular ATP levels determine cell death fate by apoptosis or necrosis. Cancer Res 1997; 57:1835-1840.

39 Leist M, Single B, Castoldi AF, Kuhnle S, Nicotera P. Intracellular adenosine triphosphate (ATP) concentration: a switch in the decision between apoptosis and necrosis. J Exp Med 1997; 185:1481-1486.

40 Kwong JQ, Henning MS, Starkov AA, Manfredi G. The mitochondrial respiratory chain is a modulator of apoptosis. $J$ Cell Biol 2007; 179:1163-77.
41 Latta M, Kunstle G, Leist M, Wendel A. Metabolic depletion of ATP by fructose inversely controls cd95- and tumor necrosis factor receptor 1-mediated hepatic apoptosis. J Exp Med 2000; 191:1975-1986.

42 Liu J, Zheng H, Tang M, Ryu X, Wang X. A therapeutic dose of doxorubicin activates ubiquitin-proteasome system-mediated proteolysis by acting on both the ubiquitination apparatus and proteasome. Am J Physiol Heart Circ Physiol 2008; 295:H2541-2550.

43 Yang H, Zhou P, Huang H, et al. Shikonin exerts antitumor activity via proteasome inhibition and cell death induction in vitro and in vivo. Int J Cancer 2009; 124:2450-2459.

44 Dong X, Liu J, Zheng H, et al. In situ dynamically monitoring the proteolytic function of the ubiquitin-proteasome system in cultured cardiac myocytes. Am J Physiol Heart Circ Physiol 2004; 287:H1417-1425.

45 Humphrey SM, Holliss DG, Seelye RN. Adenine pool catabolism in the ischemic, the calcium-depleted ischemic, and the substrate free anoxic isolated rat heart: relationship to contracture development. J Mol Cell Cardiol 1984; 16:11271136. 